\title{
Acute rheumatic fever in Jordanian children
}

I. Khriesat, ${ }^{1}$ A. Najada, ${ }^{2}$ F. Al-Hakim ${ }^{1}$ and A. Abu-Haweleh ${ }^{1}$

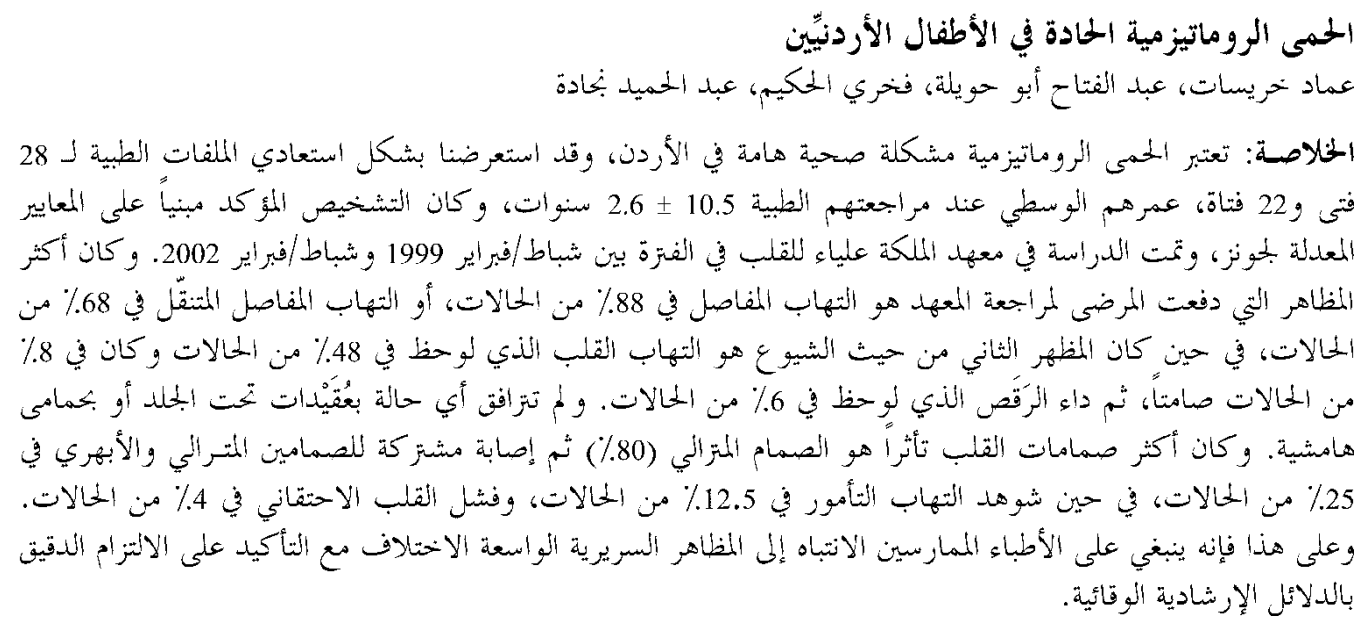

ABSTRACT Rheumatic fever remains a significant health problem in Jordan. We retrospectively reviewed medical charts of 28 boys and 22 girls (mean age at presentation $10.5 \pm 2.6$ years) with confirmed diagnosis based on modified Jones criteria at Queen Alia Heart Institute from February 1999 to February 2002. Arthritis was the commonest major manifestation ( $88 \% ; 68 \%$ migratory), carditis was second commonest ( $48 \% ; 8 \%$ silent carditis) and chorea was seen in $6 \%$. None had subcutaneous nodules or erythema marginatum. The mitral valve was most commonly affected ( $80 \%)$; both mitral and aortic valves were affected in $25 \%$. Pericarditis was seen in $12.5 \%$ and acute congestive heart failure in $4 \%$. Practitioners should be aware of diverse clinical presentations and emphasize strict adherence to prophylaxis guidelines.

\section{Le rhumatisme articulaire aigu chez des enfants jordaniens}

RESUME Le rhumatisme articulaire demeure un important problème de santé en Jordanie. Nous avons procédé à une étude rétrospective des dossiers médicaux de 28 garçons et 22 filles (âge moyen lors de la survenue 10,5 $\pm 2,6$ ans), chez lesquels le diagnostic avait été confirmé sur la base des critères de Jones révisés, à l'Institut cardiologique de la reine Alia de février 1999 à février 2002. L'arthrite était la manifestation majeure la plus fréquente $(88 \% ; 68 \%$ migratrice) suivie par la cardite (48 \%;8\% cardite silencieuse) et la chorée était observée chez $6 \%$ des patients. Aucun n'avait de nodules sous-cutanés ou d'érythème marginé. La valve mitrale était le plus fréquemment atteinte $(80 \%)$; les valves mitrales et aortiques étaient toutes deux atteintes chez $25 \%$ des sujets. Une péricardite était observée chez $12,5 \%$ et une insuffisance cardiaque congestive aiguë chez $4 \%$ des sujets. Les praticiens devraient connaître les diverses présentations cliniques et souligner l'importance du respect strict des directives pour la prophylaxie.

${ }^{1}$ Queen Alia Heart Institute, Paediatric Cardiology Division, Amman, Jordan ${ }^{2}$ Department of Paediatrics, King Hussein Medical Centre, Amman, Jordan. Received: 30/06/02; accepted: 17/02/03

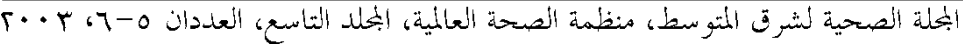




\section{Introduction}

Acute rheumatic fever is a common and serious public health problem in developing countries $[1,2]$. At the end of the 20th century, after an apparent decline, acute rheumatic fever constitutes a great challenge to industrialized and developing countries [3$6]$. In the 1980s and early 1990s when many clinicians were hoping that it was a disease of the past, anxieties were renewed when outbreaks were reported in several areas around the United States [7].

Rheumatic valvular heart disease, an important sequel to rheumatic fever, is the most common acquired heart disease worldwide and is the major cause of cardiovascular death during the first 5 decades of life in developing countries $[2,8,9]$.

Rheumatic valvular heart diseases are associated with severe, incapacitating haemodynamic disturbances in young adults and children $[1,10]$. Many patients are seen with established rheumatic heart disease at their first visit [10]. Acute rheumatic fever can mimic many other diseases and because the diagnosis is based on clinical criteria, it is still under-diagnosed or overdiagnosed in different settings [3]. Prevention of chronic rheumatic heart disease is feasible and cost effective if secondary prophylaxis is started and maintained regularly [11,12].

These facts emphasize the importance of accurate diagnosis, prompt treatment and secondary prophylaxis. In the present study we retrospectively describe the clinical profile of acute rheumatic fever in Jordanian children to increase the awareness of practitioners involved in the health care of young children.

\section{Methods}

Medical charts of children with acute rheumatic fever seen at Queen Alia Heart Insti- tute between February 1999 and February 2002 were retrospectively reviewed. Data were obtained and where further information was needed the patient was clinically reviewed and/or echocardiography was performed. The age of the study population ranged from 6 to 15 years. Diagnosis of acute rheumatic fever was based on the 1992 update of the Jones criteria [4].

Data obtained included clinical profile and standard laboratory investigations including complete blood count, sedimentation rate, $\mathrm{C}$ reactive protein level, antistreptolysin $\mathrm{O}$ titre, throat swab culture, chest radiography and electrocardiography.

Cross-section echocardiography and colour Doppler evaluation were performed within 2-3 days of presentation and after 2-3 weeks. Multiple cross-section views were usually taken from parasternal apical and subcostal positions according to the recommendations of the American Society of Echocardiography. Criteria for pathological valvular regurgitation agreed upon by the operators included:

- colour jet seen in at least 2 planes

- mosaic colour jet

- length of the colour jet $\geq 1 \mathrm{~cm}$.

\section{Results}

Of the 50 patients in the study, 28 were male and 22 were female (male to female ratio $1.3: 1$ ).

The mean age of the study population was $10.5 \pm 2.6$ years. Arthritis was the most common presenting feature $(88 \%$ of total) and was migratory in 30 and monoarticular in 14 (68\% and 32\% respectively of those with arthritis). Carditis with both auscultatory and echo evidence was seen in 24 (48\% of total) and silent carditis with no auscultatory findings was seen in 4 (8\% of

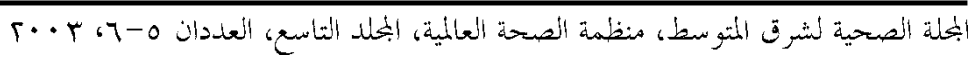


total). Chorea was seen in 3 patients, with evidence of carditis in 2 patients (Table 1). Cardiac features at presentation and 2-3 weeks later are shown in Table 2.

Table 3 shows results of laboratory investigations. Throat swabs were requested for 20 patients and were positive for group A streptococcus in only 8\%. Antistreptolysin O titres ranged from 350-1250 IU with mean (standard deviation) of 520 (320). Erythrocyte sedimentation rate was elevated in $74 \%$ with a range of $65-125$ $\mathrm{mm}$ in the first hour and $\mathrm{C}$ reactive protein was positive in $75 \%$ with a titre range of 74-104 IU.

\section{Discussion}

Rheumatic fever continues to be a major health problem in developing and industrialized countries, especially since the recent outbreaks that emphasized the need for practitioners to remain vigilant and to maintain prevention efforts [13]. Although the

Table 1 Clinical features of the 28 boys and 22 girls aged 6-15 years with diagnosed acute rheumatic fever

\begin{tabular}{lrr}
\hline Features & No. & $\%$ \\
\hline Sex & 28 & 56 \\
$\quad$ Male & 22 & 44 \\
$\quad$ Female & 44 & 88 \\
Arthritis $\quad 30$ & 68 \\
$\quad$ Migratory & 14 & 32 \\
$\quad$ Monoarthritis & 24 & 48 \\
Carditis & 3 & 6 \\
Chorea & 0 & 0 \\
Erythema marginatum & 0 & 0 \\
Subcutaneous nodules & 0 \\
\hline
\end{tabular}

Mean age \pm standard deviation of the patients = $10.5 \pm 2.6$ years. criteria for diagnosis are well known, the clinical symptoms needed to diagnose do not always appear concurrently and the initial illness may be mild or short-lived and diagnosis may be missed.

The Jones criteria were introduced in 1944 as a set of clinical guidelines for the diagnosis of rheumatic fever $[4,14]$. The manifestations of rheumatic fever were divided into major and minor categories in the Jones criteria. Major manifestations were least likely to lead to an improper diagnosis and included carditis, joint symptoms, subcutaneous nodules and chorea. History of rheumatic fever or rheumatic heart disease was also a major manifestation. Minor manifestations were suggestive of rheumatic fever, but were not sufficient for diagnosis and included clinical signs such as fever and erythema marginatum and laboratory markers of inflammation. The presence of 2 major or 1 major and 2 minor manifestations provided reasonable evidence of rheumatic activity. However, because previous history of definite rheumatic fever or rheumatic heart disease was a major criterion, the presence of a minor manifestation was sufficient to establish the diagnosis of rheumatic fever recurrence.

To improve specificity, these guidelines have been periodically modified [15-18]. In the first modification [17], objectively identifiable arthritis replaced joint symptoms as a major manifestation and arthralgia was assigned to the category of minor manifestations. History of previous rheumatic fever or rheumatic heart disease was downgraded to the minor category, and therefore, documentation of a major manifestation became necessary for the diagnosis of recurrence of rheumatic fever. Meanwhile, erythema marginatum was recommended as a major criterion. Most importantly, the evidence of preceding

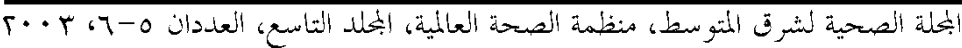




\begin{tabular}{|c|c|c|c|c|}
\hline \multirow[t]{2}{*}{ Cardiac findings } & \multicolumn{2}{|c|}{ At presentation } & \multicolumn{2}{|c|}{ After 2-3 weeks } \\
\hline & Clinical & $\begin{array}{l}\text { 2D echo- } \\
\text { Doppler }\end{array}$ & Clinical & $\begin{array}{l}\text { 2D echo- } \\
\text { Doppler }\end{array}$ \\
\hline Mitral & $18(75.0)$ & $18(75.0)$ & $18(75.0)$ & $18(75.0)$ \\
\hline Mitral and/or aortic & $3(12.5)$ & $5(21.0)$ & $4(16.5)$ & $5(21.0)$ \\
\hline Pericarditis & $3(12.5)$ & $3(12.5)$ & $2(8.0)$ & $3(12.5)$ \\
\hline Congestive heart failure & $1(4.0)$ & $1(4.0)$ & $0(0)$ & $0(0)$ \\
\hline
\end{tabular}

Values given are No. (\%) of patients.

group A streptococcal pharyngitis was added to the list of minor manifestations in the modified Jones criteria [17]. Evidence of a prior streptococcal infection was essential for the diagnosis of rheumatic fever in the 1965 revision of Jones criteria and it was suggested that exclusion of clinical syndromes of non-streptococcal origin would further increase the accuracy of the criteria [15]. The increased specificity adversely affected the sensitivity and $25 \%$ of the rheumatic fever cases diagnosed by modified criteria could not be diagnosed by revised Jones criteria [15-17]. Such cases usually presented in relatively late phases of the disease or with delayed manifestations of rheumatic fever, when anti-streptococcal antibody titres suggestive of preceding streptococcal infection had already normalized. Therefore, late manifestations of rheumatic fever were subsequently exempted from the requirement of elevated anti-streptococcal antibody titre [18].

In our study, all patients fulfilled the diagnostic modified Jones criteria [4]. Arthritis was the most frequent manifestation $(88 \%)$ as has been reported in many studies $[13,19]$. Migratory arthritis typical of rheumatic arthritis was seen in $68 \%$ and monoarticular arthritis was seen in $32 \%$ of those with arthritis. The possibility of rheumatic fever should be considered for any patient with monoarticular arthritis; it is not necessary for arthritis to be migratory to consider this diagnostic possibility. Diagnosis of a primary episode of rheumatic cardi-

\begin{tabular}{lccc}
\hline Table 3 Laboratory investigations & & & \\
\hline Laboratory test & No. (\%) & Mean (s) & Range \\
\hline Positive throat swab culture & $2 / 20(8)$ & NA & NA \\
Elevated antistreptolysin O titre (IU) & $41 / 50(82)$ & $520(320)$ & $350-1250$ \\
$\begin{array}{l}\text { Elevated erythrocyte sedimentation } \\
\quad \text { rate (mm/h) }\end{array}$ & $37 / 50(74)$ & $55(43.8)$ & $65-125$ \\
Positive C reactive protein (IU) & $30 / 40(75)$ & $39(35.5)$ & $74-104$ \\
\hline
\end{tabular}

$\mathrm{s}=$ standard deviation.

$N A=$ not applicable.

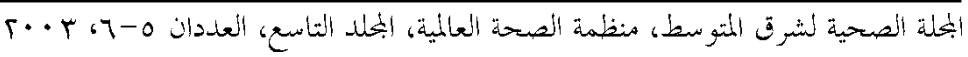


tis is based on presence of significant apical systolic and/or basal diastolic murmurs, clinical presence of pericarditis or unexplained congestive heart failure. With suboptimal auscultation skills, an echoDoppler study will quickly determine the presence or absence of a clinically detectable murmur $[20,21]$.

Clinically manifest mitral or aortic regurgitation is still the diagnostic hallmark of acute rheumatic carditis [5,22]. Our findings confirm previous reports that echoDoppler can detect significant valvular incompetence in the absence of auscultatory finding [23,24]. In our study, 4 patients had silent carditis ( $8 \%$ of total); 2 of the silent carditis cases were evident at presentation and 2 became clinically evident at $2-$ 3 weeks follow-up. The incidence of subclinical carditis was low compared with previous reports in which silent carditis accounted for $30 \%-50 \%$ of cases. Patients may seek medical advice late in the course of the disease when clinical valvular involvement is evident. This agrees with a report from New Zealand where all patients with silent carditis developed an audible murmur within 2 weeks of onset $[23,24]$.

There is a great disparity in the proportion of cases of acute rheumatic fever with chorea between different populations from many industrialized and developing countries [5,25-27]. Chorea manifested in only $6 \%$ of our patients, in agreement with reports from Africa, South and East Asia, the Pacific and the Arabian Peninsula, where chorea was reported in less than $15 \%$ of all cases of acute rheumatic fever [26]. In studies from the United States of America, Pakistan and Turkey, chorea manifested in higher proportions, i.e. up to $52 \%$ of cases [27].

Our patients had neither subcutaneous nodules nor erythema marginatum, similar to a report from Saudi Arabia where erythema marginatum and subcutaneous nodules were infrequent [19].

Sibling studies have suggested an inherited susceptibility to patterns of acute rheumatic fever [28]. Studies from the USA and the Caribbean have identified a B cell alloantigen (D8/17), present in high percentage of B cells from patients with acute rheumatic fever and their family members [29]. This however was not found among an Indian population with acute rheumatic fever [30]. This may give a clue to the pathogenesis of acute rheumatic fever and may explain how populations may differ in their immune responses to group A streptococcal infections and develop different rates of certain clinical manifestations of acute rheumatic fever.

Laboratory investigations are of great support to the diagnosis, including evidence of streptococcal infection. In our patients, antistreptolysin $\mathrm{O}$ titre was substantially higher, as has been reported in another study [31].

Acute phase reactants were significantly elevated in approximately three-quarters of patients with acute rheumatic fever [32].

Increased susceptibility to recurrences of rheumatic fever appears to last into adulthood, therefore, we must optimize the clinical diagnosis procedure and ensure long-term adherence to secondary prophylaxis [33].

Acute rheumatic fever continues to be a major public health problem in Jordan and results in economic burdens and serious health sequelae. Practitioners should be more aware of this health problem, should consider this diagnostic possibility when appropriate and should ensure strict and long-term adherence to secondary prophylaxis.

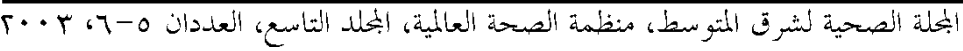




\section{References}

1. Bavdekar SB, Soloman R, Kamat JR. Rheumatic fever in children. Journal of the Indian Medical Association, 1999, 97(12):489-92.

2. Nordet P. World Health Organization/International Society and Federation of Cardiology Global Programme for the Prevention and Control of Rheumatic Fever/Rheumatic Heart Disease. Heartbeat, 1993, 3:4-5.

3. Da Silva NA, Pereira BA. Acute rheumatic fever. Still a challenge. Rheumatic diseases clinics of North America, 1997, 23(3):545-68.

4. Dajani AS et al. Guidelines for the diagnosis of rheumatic fever: Jones criteria, updated 1992. Journal of the American Medical Association, 1992, 268:206973.

5. Veasy LG, Tani L, Hill H. Persistence of acute rheumatic fever in the intermountain area of the United States. Journal of pediatrics, 1994, 124:9-16.

6. Zangwill KM, Wald ER, Londino A. Acute rheumatic fever in Western Pennsylvania: a persistent problem into the 1990s. Journal of pediatrics, 1991, 118:561-3.

7. Taubert KA, Rawley AH, Shulman ST. Seven year national survey of Kawasaki disease and acute rheumatic fever. Pediatric infectious disease journal, 1994, 13:704-8.

8. Eisenberg MJ. Rheumatic heart disease in the developing world: Prevalence, prevention and control. European heart journal, 1993, 14:122-8.

9. Haffejee I. Rheumatic fever and rheumatic heart disease: the current status of its immunology, diagnostic criteria and prophylaxis. Quarterly journal of medicine, 1992, 84:641-58.
10. Haffejee IE. Rheumatic fever. Bailliere's clinical rheumatology, 1995, 9(1):11-20.

11. Tampkins DG, Boxerbaum B, Liebman J. Long-term prognosis of rheumatic fever patients receiving regular intramuscular benzathin penicillin. Circulation, 1972, 45:543-51.

12. Nordet P. World Health Organization programme for the prevention of rheumatic fever/rheumatic heart disease in 16 developing countries: report from phase I (1986-90). Bulletin of the World Health Organization, 1992, 70:213-8.

13. David L. Diagnosis and treatment of rheumatic fever. Archives of pediatrics, 1998, 5(6):681-6.

14. Jones TD. Diagnosis of rheumatic fever. Journal of the American Medical Association, 1994, 126:481-4.

15. Stollerman GH et al. Report of the Adhoc Committee on Rheumatic Fever and Congenital Heart Disease of American Heart Association: Jones Criteria (revised) for guidance in the diagnosis of rheumatic fever. Circulation, 1965, 32: 664-8.

16. Okuni M. Problems in clinical application of revised Jones diagnostic criteria for rheumatic fever. Japanese heart journal, 1971, 12:436-41.

17. Rutstein DD et al. Report of the Committee on Standards and Criteria for Programs of Care of the Council of Rheumatic Fever and Congenital Heart Disease of American Heart Association. Jones criteria (modified) for guidance in the diagnosis of rheumatic fever. Circulation, 1956, 13:617-20.

18. Shulman ST et al. Committee on Rheumatic Fever, Endocarditis and Kawasaki Disease of the American Heart Associa- 
tion. Jones Criteria (Revised) for guidance in the diagnosis of rheumatic fever. Circulation, 1984, 70:204A-48A.

19. Abbag $F$ et al. Acute rheumatic fever in Southern Saudi Arabia. East African medical journal, 1998, 75(5):279-81.

20. St. Clair EW et al. Assessing house staff diagnostic skills using a cardiology patient simulator. Annals of internal medicine, 1992, 117:751-6.

21. Mangione $S$ et al. The teaching and practice of cardiac auscultation during internal medicine and cardiology training. Annals of internal medicine, 1993, 119: 47-54.

22. Dajani AS, Allen HD, Taubert KA. Echocardiography for diagnosis and management of rheumatic fever [letter]. Journal of the American Medical Association, 1993, 269:2084.

23. Folger GM et al. Occurrence of valvar heart disease in acute rheumatic fever without evident carditis: Colour-flow Doppler identification. British heart journal, 1992, 67:434-8.

24. Abernethy $M$ et al. Doppler echocardiography and early diagnosis of carditis in acute rheumatic fever. Australia and New Zealand journal of medicine, 1994, 24:530-5.

25. Lue $\mathrm{HC}$ et al. The natural history of rheumatic fever and rheumatic heart disease in the Orient. Japanese heart journal, 1979, 20:237-52.

26. Lahiri K, Rane HS, Desai AG. Clinical profile of rheumatic fever: a study of 168 cases. Journal of tropical pediatrics, 1985, 31:273-5.

27. Pilapil VR, Watson DG. Rheumatic fever in Mississippi: 104 cases seen over a decade. Journal of the American Medical Association, 1971, 215:1626-30.

28. Spagnuolo M, Taranta A. Rheumatic fever in siblings: similarity in its clinical manifestations. New England journal of medicine, 1968, 278:1843-8.

29. Khanna AK et al. Presence of a non-HLA $B$ cell antigen in rheumatic fever patients and their families defined by a monoclonal antibody. Journal of clinical investigation, 1989, 83:1710-6.

30. Kaur S et al. Ethnic differences in expression of susceptibility marker(s) in rheumatic fever/rheumatic heart disease patients. International journal of cardiology, 1998, 64:9-14.

31. Taranta A, Stollerman GH. The relationship of Sydenhams chorea to infection with group A streptococci. American journal of medicine, 1956, 20:170-5.

32. Taranta A et al. Determination of C-reactive protein in serum as a guide to the treatment and management of rheumatic fever. American journal of medicine, 1953, 15:645-55.

33. Johnson EE, Stollerman GH, Grossman BJ. Rheumatic recurrence in patients not receiving continuous prophylaxis. Journal of the American Medical Association, 1964, 190:407-13.

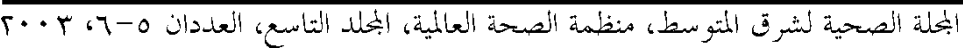

